\title{
Is Mother-Tongue Education Possible in a Language-Diverse Province? A Case of Limpopo Province
}

\section{Prof Rachael Jesika Singh}

\author{
Research Development and Administration Department, University of Limpopo, South Africa
}

Email: Jesika.Singh@ul.ac.za

\section{Doi:10.5901/mjss.2014.v5n25p141}

\begin{abstract}
Mother tongue instruction in education is practiced in many countries across the world. The South African scenario is unique in this regard. Whilst many nations have identified one national language by which their populace can be identified, in South Africa, there are eleven such languages. The problem is that many of the South African languages are indigenous to specific provinces. In the Limpopo province, for example, three official indigenous African languages are spoken. This makes instruction in the mother tongue complex. This study examined mother tongue instruction in schools in the Limpopo province. The aim of the study was to investigate whether mother tongue instruction is possible in a province that has three African indigenous languages, in addition to English and Afrikaans. Data was collected using questionnaires and interviews. The sample consisted of schools in areas of the province where the different languages are spoken. In addition, the sample also consisted of schools from multicultural settings, mainly found in urban areas. In total 12 schools were selected. The data was analysed qualitatively and quantitatively. The data revealed that mother tongue education is possible in situations where all the children speak one or two of the national languages. Where more than two languages are spoken as mother tongue, there are challenges determining the medium of instruction. The biggest challenge in such a case is the provision of learner-support materials (LSM). Another associated challenge is class size. Broader challenges include shortages of suitably qualified teachers. Recommendations of this study are: mother tongue instruction must be approached and funded systemically; learnersupport materials must be developed before implementation of such a system; mother tongue instruction should also be available in multicultural schools; school facilities should be standardised so that demand on well-resourced schools is minimised.
\end{abstract}

Keywords: mother tongue instruction, language, multicultural, LSM, facilities

\section{Introduction}

Any discussion about languages delves deeply into the history, politics, identities, imagination and aspiration of a people (Menon, Viswanatha \& Sahi, 2014, p. 42). In the case of South Africa, the historical issues related to language relate to two major concepts, namely colonialism and apartheid (Cherian \& Du Toit, 2008). Colonialism introduced two dominant languages to South Africa; that is, English and Afrikaans. These two languages still dominate the South African language today and are two of the eleven official languages of the country (Olivier, 2013). Apartheid brought about a separation between black people and other race groupings. Black people were forcefully placed in designated homelands and educated in their mother tongue (African language). English and Afrikaans were later introduced in the curriculum. The Bantu Education Act of 1953 was designed, under the guise of Christian ideology, to suppress black people through indoctrinationusing a separated system of education based along racial lines. In the Limpopo province, three Bantustans were created: Gazankulu, Lebowa and Venda. These homelands were created so that blacks "could be divided into their ethnic affiliations and forced to live in designated areas supposedly tied to their ethnic history" (Cherian \& Du Toit, 2008, p. 109). With the dismantling of apartheid in 1994 came a new democratic constitution which promoted multicultural education and multilingualism (Olivier, 2013). However, the problem of the apartheid legacy still lingers and language is still used as a means of unofficially separating children in the schooling system. For example, Afrikaans medium schools still cater exclusively for Afrikaans-speaking children. Many of these schools have English medium classes as well. In recently years, mother tongue instruction (usually in an African language), especially in the foundation phase (grades 1-3) has been introduced. Most other schools used English as the medium of instruction. In rural areas, mother tongue instruction is used up to grade 3. "Around the world, education in rural areas of developing countries - especially those that are linguistically diverse - is typically of low quality" (Schroeder, 2004, p. 376).

The language policy of the government is additive multilingualism, meaning that the use of more than one 
language is actively promoted by the government. Ironically, many black parents still prefer to send their children to English medium schools because they believe that English is associated with upward social mobility and creates better employment opportunities as well. Across the country, English is commonly used as the primary means of communication. In the Limpopo province, which is a predominantly rural province, three major indigenous languages are spoken: Northern Sotho (of which Sepedi is a common variant), Xitsonga and Tshivenda. There are many dialectical variants of these languages as well. English and Afrikaans are also commonly used. According to Cherian and Du Toit (2008), this makes the Limpopo province the most linguistically diverse province in South Africa. Coupled with this linguistic diversity is the question of whether or not mother-tongue education is possible in such a setting. This paper sets out to examine the concepts of mother-tongue education and multilingualism, discuss examples of mother-tongue education in various countries (including African countries), present theories of language acquisition (especially second language), examine South African languages policies, and then present the findings from the study conducted on in language diverse schools of Limpopo province.

\section{Mother-Tongue Education and Multilingualism}

Mother-tongue in education refers to the use of the native language or the first language to teach at formal and nonformal levels (Abijo, 2014, p. 124). According to Butzkamm \& Caldwell (2009, p. 66), the mother-tongue is the greatest asset any human being to the tasks of foreign language learning, "It provides an indispensable Language Acquisition Support System". Without the use of the mother-tongue, children's potential is often wasted resulting in educational failure and a lack of development (Mackenzie \& Walker, 2013). It is for this reason that the United Nations Educational, Scientific and Cultural Organisation (UNESCO) have encouraged mother-tongue instruction in early childhood and primary education since 1953 (UNESCO, 1953). Hovens (2002) states that mother-tongue education especially benefits disadvantaged groups, including children from rural communities. This is especially significant in a rural context like the Limpopo province. According to studies, UNESCO $(2010$, p. 2) reports that, "six to eight years of education in a language are necessary to develop the level of literacy and verbal proficiency required for academic achievement in secondary school". In addition, UNESCO (2010) also states that in order to lay a cognitive and linguistic foundation in learning an additional language, fluency and literacy in the mother-tongue is very important and that the success of the mothertongue based multilingual initiatives depends onother factors such as health, economic status, social status and conditions and the political and economic environment. Usually, children start learning a second/foreign language when they go to school. By this time, they have already grasped the following in the mother-tongue: conceptualization of the world, communication, development of own voice, understanding of grammar, secondary skills of reading and writing (Butzkamm \& Caldwell, 2009). What usually happens at this stage is called transference into the second language (Nel \& Swanepoel, 2010) where they use the concepts/skills acquired in the mother-tongue to learn the second language. This can take place successfully only if they are sufficiently proficient in the mother-tongue (The World Bank, 2005). Usually there are linguistic gaps between the mother-tongue and the second language or language of instruction. In the South African context, whilst there is a policy of multilingual education, the model used may be inefficient (Mackenzie \& Walker, 2013). This means that the rural settings in which mother-tongue instruction occur make lack certain pedagogical inputs. Mother-tongue instruction helps to make education more relevant to students' home cultures by integrating the school with the surrounding community and teachers who use mother-tongue can more easily and effectively integrate local expertise and indigenous knowledge systems into the formal curriculum; it is also connected to increased student involvement in learning (Laguarda \& Woodward, 2013). An estimated 70 per cent of people on earth speak two or three languages; multilingualism is increasingly recognised as the norm across the world (Menon et al., 2014). However, successful mother-tongue instruction and multilingual education does occur in other countries, both in Africa and elsewhere. Therefore, the next section examines the models of mother-tongue instruction that occur in these countries. The intention is to look for similarities with the South African context and to learn from best practice in other countries.

\section{Examples of Mother-Tongue Education from Africa and Around the World}

Chitera's (2012) study examined the conflicts of Language-in-Education policies (LiEP) in relation to the promotion of home languages as the language of teaching and learning of Malawian mathematics teachers. The problem was that although the LiEP was in place for fifteen years, little was done in teacher training colleges to support teachers with its implementation. This resulted in mathematics teachers struggling to cope with the teaching of mathematics in bi/multilingual classrooms. This was because their own prior teacher training programme did not include training courses in diversity of language practices. The recommendation was that the LiEP at higher education provides the mathematics 
teacherswith the flexibility of being able to use multiple languages freely, which will allow them to code-switch in their classrooms.

Laguarda and Woodward's (2013) study focused on mother-tongue instruction for indigenous Kuku children in Southern Sudan where they launched a programme for teachers and volunteers with the help of an international nongovernmental organization. According to the study, in South Soudan, mother-tongue instruction is practically nonexistent, despite being the official policy of the ministry of education. Therefore their argument was that it is a basic pedagogical principle that new knowledge and concepts are best built on a foundation of already existing understanding. They found that the programme that lasted for a 14-week trimester was embraced by students, parents, teachers and government officials. This led to other schools implementing mother-tongue instruction as well. The researchers felt that through this programme they were able to demonstrate to government officials what is possible and how well-intentioned but under-resourced policies can be implemented.

Awedoba's (2001) study examined attitudes towards instruction in the local language in Ghana. He contends that whilst Ghanaian educational policy has prescribed local languages as media of instruction for at least the first three years of basic education, in many cases the policy is not applied. This they attribute to the unpopularity of mother-tongue education as medium of instruction with government, policymakers, teachers, parents and pupils. The study found that the use of first language as the medium of instruction was counter-productive. This resulted in the policy being ignored and English was preferred as the medium of instruction. There seemed to be a perception that subjects like the sciences and mathematics cannot be taught effectively in the local languages.

Schroeder's (2004) study examined mother-tongue education in schools in Kenya amongst Tharaka-speaking children. In Kenya, Swahili is the national language and English is the official language with 61 languages used in total. Similar to other African countries, most of the indigenous African languages native to Kenya is not used in formal education, although mother-tongue education is allowed up to grade 3 . The study reported on a poor, rural community that needed some kind of educational improvement and the implementation of a new strategy in the form of a mothertongue programme was considered an improvement. Due to positive uptake by all stakeholders, the programme was able to continue even when the funding was no longer available. Some positive outcomes of the programme included educationists writing their folktales, creating new stories, documenting historical and cultural information in textbooks, and putting their songs in print.

Abijo's (2014) study examined emerging trends in the use of mother-tongue as a language of instruction in lower Nigerian primary schools.According to Abijo (2014), in most cases Nigerian children are not privileged to be taught in the mother-tongue. They have to contend with the language of wider communication, which is English. This has led to the marginalisation of Nigerian indigenous languages like Yoruba, which is spoken in eight states in Nigeria and used as the language of instruction for the first three years of schooling. The study recommended that the mother-tongue policy should be enforced by the government; language teachers should use only Yoruba as the medium of instruction; compliance with the policy by school administrators; and adequate teaching materials should be made available to the Yoruba language teachers in order to enhance effective language teaching.

Issues of mother-tongue instruction are commonplace in many countries beyond Africa as well. For example, in India, Menon et al. (2014) examined the potential role of languages in teacher education programmes in multilingual contexts. Their understanding of language is as follows: it is socially situated in relations of power, language is a socially set of practices or discourses; and language proficiencies in multilingual contexts are viewed in terms of emergent and intersecting proficiencies. Their discussion centres on the use of English and other local and regional languages in India. They state that teachers have a significant role to play in responding to language policies that could affect their students positively or adversely. They conclude that "regional languages in India have a robust, rich and complex history, and need to be kept alive, dynamic and functional - even as we widen access to English for a large number of people" (Menon et al., 2014, p. 61).

According to Mackenzie and Walker (2013), it is important to learn from the experiences of others (case studies) that support mother-tongue learning. They cite a few examples of best practice: in India materials were developed in the mother-tongue to improve the reading and achievement levels of learners in eight minority languages in Andhra Pradesh and Orissa; in the Philippines, their mother-tongue-based education programme contained a series of bilingual traditional stories of Lubuagan prepared by teachers which reflect the culture and lifestyle of the students; and in Yucatan, Mexico where the 'language nest' approach is used as an immersion-based methodology to revitalise the Mayan language and culture and to foster an understanding of indigenous traditions. They conclude that there are some broad lessons that can be drawn from these experiences for by governments of different countries (Mackenzie and Walker, 2013, p. 16-17):

- Show strong political will to introduce mother-tongue learning;

- Introduce language policies which ensure that early education is carried out in the mother-tongue; 
- Support the development of low-cost mother-tongue learning materials through flexible textbook and reader purchasing, developing relevant local skills and techniques for the production of literacy materials, involving local teachers and community in developing materials, and ensuring good language documentation for nonscripted languages;

- Support teachers to effectively deliver a multi-language policy through prioritising early literacy in local languages through teacher training; development of appropriate recruitment and training approaches;

- Invest in multi-lingual teaching by increasing financial support; and

- Build a supportive community environment by providing information on the status and function of languages and culture.

In understanding mother-tongue education, it is also important to explore a very important key concept, that is, language acquisition. There are many theories on language acquisition and second language acquisition. They attempt to explain or understand this complex process. Furthermore, factors that are involved in language acquisition in different social and cultural contexts also play a role in acquiring a language. The next section examines a few significant theories related to language learning.

\section{Theories of Language Learning}

Noam Chomsky (1965) believes that children are born with an inherited ability to learn any human language. He coined the term 'language acquisition device' (LAD) which he claims that every child is born with. This LAD encodes the major principles of a language and its grammatical structures into the child's brain. According to Chomsky $(1965,25)$, children only have to learn new vocabulary and apply the syntactic structures from the LAD to form sentences. He believes that children cannot learn from imitation alone as languages are very complex, however, all children become fluent in their native language within five or six years. This theory has been both supported and criticised over the years. Interaction with people (social) is a critical element of the learning process. Social learning theory is seen as a bridge between behaviourist and cognitive theory because it encompasses attention, memory and motivation. Bandura's Social Learning Theory posits that people learn from one another through observation, imitation and modelling (Bandura, 1977).

According to Krashen $(1985,2)$, "Humans acquire language in only one way - by understanding messages, or by receiving comprehensible input". This comes from his earlier Monitor Model (1982) of second language acquisition which was described using five hypotheses: acquisition-learning hypothesis (acquire through no conscious attention to language form; learn through conscious attention to form and rule learning); monitor hypothesis (acquired system initiates utterances and is responsible for spontaneous language use; learned system acts as an editor or monitor, making minor changes and polishing what the acquired system has produced); natural order hypothesis (second language acquisition unfolds in predictable consequences - the language features that are easiest to state are not necessarily the first to be acquired); input hypothesis (acquisition occurs when one is exposed to language that is comprehensible and includes a step beyond that level $-\mathrm{i}+1$ ); affective filter hypothesis (affective filter is a metaphorical barrier that prevents learners from acquiring language even when appropriate input is available - refers to feelings, needs, attitudes and emotional state).

Another leading authority on second language acquisition is Cummins. Central to Cummins (1979) work is the distinction that he makes between the two kinds of language proficiencies - Basic Interpersonal Communication Skills (BICS) and Cognitive Academic Language Proficiency (CALP). The BICS are 'surface' skills of listening and speaking that are typically acquired quickly by many students, especially by those from language backgrounds similar to English who spent a lot of time in school interacting with native speakers. CALP is the basis for a child's ability to cope with the academic demands from various subjects. It is interesting to note Cummins stance on the time take to develop these language proficiencies - while many children develop native speaker fluency (BICS) within two years of immersion in the target language, it take between five to seven years for a child to be working on a level with native speakers to acquire the academic language. Children use, what Cummins calls, common underlying proficiency (CUP) (knowledge and skills) to learn additional languages (Cummins, 2000). This means that any expansion of CUP that takes place in one language will have a beneficial effect on other languages. This has important implications in a language diverse setting like that of this study. It also emphasises the need for a sound or solid development of the mother-tongue.

\section{Language Learning in the South African Context}

South Africa is a country rich in languages and cultures. Often dubbed the 'rainbow nation', it reflects how people can live 
and learn in a democratic setting and at the same time promote and develop their cultural and language identity. South Africa has eleven official languages and English is the lingua franca of the country, although less than ten per cent of the population are native English speakers (Manyike \& Lemmer, 2010). The medium of instruction in schools (Language of Learning and Teaching - LoLT), according to the Language in Education Policy (LiEP) (1997) is mother-tongue instruction in the foundation phase (grades R to 3); the second language is introduced from grade 3 onwards. The practice of additive multilingualism is encouraged by the policy.

Having said this, the situation in schools is very complex with regard to language learning and use. For English mother-tongue learners, the learners attend an English medium school and learn additional languages according to the policy; the second language is usually a local African language or Afrikaans. The same applies for Afrikaans mothertongue learners. They attend Afrikaans medium schools and learn additional language/s after the first two to three years of schooling. For learners whose mother-tongue is an African language, the situation is slightly more complex. Learners in urban areas usually attend English medium schools and learn through a language that is not their mother-tongue. When the second language is added, the home language is usually done (usually one or two of the dominant African languages in the area). Although this contradicts the policy of mother-tongue instruction in the early years, it is usually what parents prefer. In the rural areas, where more often than not, a local African language is dominant, the medium of instruction in schools is in the mother-tongue. English is added as a second language from grade 3 onwards. However, rural areas are characterised with unique problems that affect learning in general. According to the Human Science Research Council (HSRC) (2004) and MacDonald (2006), this is a formidable challenge for the English second language learner in the South African classroom where poor environmental contexts, poor resources, large classes, inadequate textbooks, weak management structures, teachers with limited English proficiency and the general demoralization in the teaching fraternity exacerbate the problem of effective English language learning (Manyike \& Lemmer, 2010, p. 30). The Limpopo province, with the exception of a few towns, falls into this category of rural context.

\section{Research Methodology}

This study is set in the largely rural province of Limpopo which is the northern-most province of South Africa. Regarded as a rural province, Limpopo is a cultural and language-diverse province. Besides the five official South African languages in use in the Limpopo province, the languages of the neighbouring provinces and countries (Zimbabwe, Botswana and Mozambique) are also spoken in the province. In order to investigate the possibility of educating using mother-tongue instruction in this language-diverse province, a sample of 12 schools was purposively selected. All the schools were primary schools situated in different areas of the province. The criteria for selection of the schools included: schools in urban areas (one English medium, one Afrikaans medium, one dual medium) and schools in rural areas (three Sepedi medium, three Xitsonga and three Tshivenda medium). School principals in all these schools were asked to complete a questionnaire that contained close-ended questions related to the languages used at the school. They were also interviewed; the interview was semi-structured and covered the following issues: learner-support materials in the mother-tongue, availability of language teachers, general availability of resources, general English proficiency of teachers and learners and other general language issues in the school. The results from the questionnaires were analysed quantitatively and the findings from the interviews were analysed qualitatively using the thematic approach.

\section{Findings and Discussion}

\subsection{Questionnaires}

The findings from the questionnaires indicated that all 12 schools were offering 2 or more of the official languages. In schools 1, 2 and 3, which were located in urban areas, the English medium school used three languages and the Afrikaans and dual medium school used two languages. The English medium school offered instruction in English and Sepedi in the foundation phase, from grade 4 onwards, the medium of instruction is English. The additional language from grade 4 onwards is Afrikaans or Sepedi. In the Afrikaans medium school, the medium of instruction from grade 1 to 3 is Afrikaans. The additional language introduced in grade 3 is English. In the dual medium school, instruction in the foundation phase took place in Afrikaans and English.For English medium learners, the additional language is Afrikaans and for Afrikaans medium learners, the additional language is English. The languages used in the schools in the rural areas followed the same pattern. In the two schools where the medium of instruction is Sepedi in the foundation phase, the additional language introduced from grade 3 onwards is English. In the two schools where the medium of instruction in the foundation phase is Xitsonga, the additional language introduced from grade 3 onwards is English. In the two 
schools where the medium of instruction in the foundation phase is Tshivenda, the additional language introduced from grade 3 onwards is English.

From the data presented, there is a clear pattern emerging with regard to rural primary schools. Firstly, they offer only two languages; usually it is the local African language (either in Sepedi, Xitsonga or Tshivenda) which is used as the medium of instruction from grade 1 to 3 . Secondly, they all offer English as an additional language which is introduced in grade 3. Thirdly, in all these schools, the medium of instruction is English from grade 4 onwards. Introducing the second language in grade 3 and then using it as the medium of instruction in grade 4 is a potentially risky situation in such schools. It can be argued that the second language will not be developed to a level that allows for effective learning to take place. Words for basic concepts in the different subject areas will need to be learnt in English. The argument could also be that code-switching can be used in this situation. For the urban schools, clearly each context is different and presents a different set of criteria that is employed in language selection and use. What is interesting, however, is that the Afrikaans and dual medium schools do not offer an African language as an additional language whereas the English medium school is seen as the most language diverse schools in the study.

\subsection{Interviews}

The interview with principals was to establish insight into the language complexities of the schools. The data was analysed thematically and the following themes emerged from the interviews: provision of learner-support materials; resource provisioning at schools; class size; and teacher shortage. In terms of learner-support materials in the form of textbooks, for example, readers for learners, it was found that there were sufficient readers for learners in urban schools in all the different languages. In rural schools, learners had to share books. The books were available in the African languages; the problem was the number of books. The principals indicated that there is never enough money to buy readers for each child. In addition, they all mentioned the problem of non-delivery of textbooks in the Limpopo province for approximately a period of two years. This created a national outcry and the 'Limpopo textbook saga' pointed to systemic challenges regarding provision of essential learner-support materials. Additional resources used to teach languages at foundation phase level are also crucial to the development of the learners. The urban schools had resources like charts and teaching aids and multi-media resources. There was very sparse resources for teaching and learning for languages in the rural schools. Here again, funding was the main reason for non-provision of resources. Clearly, the system needs to change to create a balance in provision of teaching and learning resources. Urban schools again restricted class size to between 35 and 40 learners per class. The class size was also affected by the physical space available. The capacity of the urban schools was much smaller. In the rural areas, the physical classrooms are much bigger and some class sizes were larger, ranging from 40 to 60 . Although there are national guideline for the class size (35 in the foundation phase), the principals indicated that this was rarely followed by schools. The physical space, limited number of classrooms and teachers forced the schools to increase the size of the classes. In terms of language teaching, this can have a negative impact especially when teaching reading and writing skills - individual attention is severely restricted in such a setting. The availability of teachers was also commented on by the principals. In the urban areas, staff was not a problem as teachers are always available; however, the principals from the rural schools mentioned that staffing is always a challenge in rural schools as teachers are often unwilling to travel out to deep rural areas. In addition, unqualified teachers are not able to provide the same services especially for teaching learners language skills.

\section{Recommendations}

Based on the findings of this study, the following is recommended concerning mother-tongue education in Limpopo primary schools:

- All schools, irrespective of location, should offer an African language either as medium of instruction in the foundation phase or as an additional language.

- Provision of readers in all official languages should be a priority in terms of learner-support materials.

- Rural schools should be given priorityattention as they appear to be generally under-resourced.

- Language teachers should be trained with coping skills in rural settings.

- Policy regarding the introduction of the English medium for mother-tongue learners of African languages in grade 4 needs to be reviewed or revised. 


\section{Conclusion}

Is mother-tongue education possible in a language-diverse province such as Limpopo? Yes, it is and this province can be used as an example for the use of African languages as medium of instruction throughout the years of schooling. One very crucial factor must be factored into this debate, that is, provision of resources in African languages and more importantly, the state of rural education in South Africa. From the study, it became clearly evident that urban schools are better resourced and are able to provide a wider offering of language preferences. Although one cannot generalize from a small study such as this one, it was able to highlight the challenges faced by rural schools and in the provision of mothertongue instruction. Once again, the issue of policy presence versus policy provision was highlighted. All the relevant policies in terms of mother-tongue education are in place; it is providing for the implementation of these policies that is a challenge, especially in rural areas of South Africa.

\section{References}

Abijo, J. A. (2014). Emerging trends in the use of mother-tongue as a language of instruction in Lower Nigerian primary schools. Journal of Emerging Trends in Educational Research and Policy Studies, 5(8), 124-127.

Awedoba, A. (2001). Attitudes towards instruction in the local language - A case study of the Perspectives of the 'Small' Stakeholder. Paper read at Comparative and International Education Society Conference in Washington, USA (pp. 35-64).

Bandura, A. (1977). Social Learning Theory. New York: General Learning Press.

Butzkamm, W. \& Caldwell, J. A. W. (2009). The Bilingual Reform. A Paradigm Shift in Foreign Language Teaching. Tübingen: Narr.

Butzkamm, W. (2011). Why make them crawl if they can walk? Teaching with mother tongue support. RELC Journal, 42(3), 379-391.

Cherian, L. \& Du Toit, C. (2008). Literacy learning in Limpopo - a multilingual environment. Perspectives in Education, 26(4), 108-114.

Chitera, N. (2012). Language-in-Education policies in conflict: Lessons from Malawian mathematics teacher training classrooms. African Journal of Research in MST Education, 16(1), 58-68.

Chomsky, N. (1965). Aspects of the Theory of Syntax. MIT Press.

Cummins, J. (1979). Cognitive/academic language proficiency, linguisticinterdependence, the optimum age question and some other matters. WorkingPapers on Bilingualism, 19, 121-129.

Cummins, J. (2000). Language, Power and Pedagogy: Bilingual Children in the Crossfire. Clevedon: Multilingual Matters.

Hovens, M. (2002). Children learn better in their mother-tongue. International Journal of Bilingual Education and Bilingualism, 5(5), 1-3.

Human Sciences Research Council (HSRC). (2004). Annual Report: Emerging voices. A report on Education in South African communities. Pretoria: HSRC Press.

Krashen, S. D. (1982). Principles and Practice in Second Language Acquisition. Oxford: Pergamon.

Krashen, S. D. (1985). The Input Hypothesis: Issues and Implications. London and New York: Longman.

Laguarda, A. I. \& Woodward, W. P. (2013). They own this: Mother tongue instruction for indigenous Kuku Children in Southern Sudan. School Psychology International, 34(4), 453-469.

MacDonald, C. A. (2006). The properties of mediated action in three different literacy contexts. Theory and Psychology, 16(1), 51-80.

Mackenzie, P. J. \& Walker, J. (2013). Global Campaign for Education Policy Brief. Mother-tongue education: policy lessons for quality and inclusion. Johannesburg. [Online] Available: www.campaignforeducation.org (August 21, 2014).

Manyike, T. V. \& Lemmer, E. M. (2010). English reading and writing performance of Xitsonga-speaking grade 7 learners in township schools: A case study. Per Linguam, 26(1), 29-46.

Menon, S., Viswanatha, V. \& Sahi, J. (2014). Teaching in Two Tongues: Rethinking the Role of Language(s) in Teacher Education in India. Contemporary Education Dialogue, 11(1), 41-65.

Olivier, J. (2013). The accommodation of multilingualism through blended learning in two Information Technology classes. Perspectives in Education, 31(4), 43-57.

Schroeder, L. (2004). Mother-tongue education in schools in Kenya: Some hidden beneficiaries. Language Matters, 35(2), $376-389$.

Swanepoel, E. \& Nel, N. (2010). Do the language errors of ESL teachers affect their learners? Per Linguam, 26(1), 47-60.

The World Bank. (2005). "Education notes: In their own language...Education for All". [Online] Available: http://siteresources.worldbank. org/EDUCATION/Resources/Education-Notes/EdNotes_Lang_of_Instruct.pdf (August 21, 2014).

UNESCO. (1953). The use of vernacular languages in education. Paris: UNESCO.

UNESCO. (2010). Enhancing learning of children from diverse language backgrounds: Mother tongue-based bilingual or multilingual education in the early years. 2010/ED/BAS/ECCE/PI/1. Paris: UNESCO. 